\title{
Th17 Cytokines Regulate 0steoclastogenesis in Rheumatoid Arthritis
}

\author{
Kyoung-Woon Kim, ${ }^{*}$ Hae-Rim Kim, ${ }^{\dagger}$ Bo-Mi Kim, ${ }^{*}$ Mi-La Cho, ${ }^{* \ddagger}$ and Sang-Heon Lee ${ }^{\dagger}$
}

\begin{abstract}
From the Conversant Research Consorcium in Immunologic Disease, * Seoul St. Mary’s Hospital, College of Medicine, and the Rheumatism Research Center, ${ }^{\ddagger}$ The Catholic University of Korea, Seoul; and the Division of Rheumatology, ${ }^{\dagger}$ Department of Internal Medicine, Konkuk University School of Medicine, Seoul, Republic of Korea
\end{abstract}

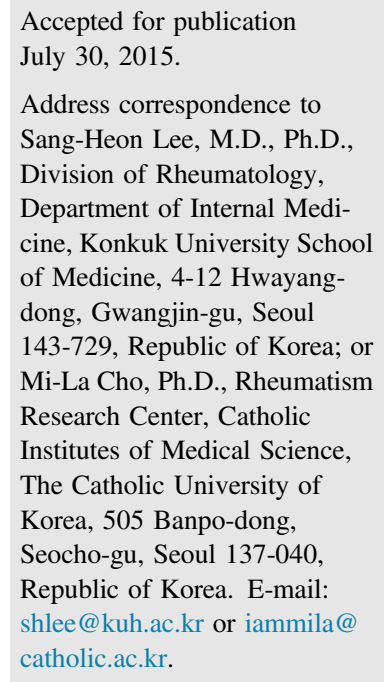

\begin{abstract}
This study determined the effect of type 17 helper T-cell (Th17) cytokines on osteoclastogenesis in rheumatoid arthritis (RA). The expression of IL-17 and receptor activator of NF- $\kappa B$ ligand (RANKL) was determined in synovial tissue, fibroblast-like synoviocytes (FLSs), and synovial fluids of RA patients using immunostaining and enzyme-linked immunosorbent assay. Th17 cytokine-induced RANKL expression was studied in RA FLS by using real-time PCR, luciferase activity assays, and Western blot analysis. Human peripheral blood monocytes were cultured with macrophage colony-stimulating factor and Th17 cytokines, after which osteoclastogenesis was evaluated by counting the number of tartrateresistant acid phosphatase-positive multinucleated cells. Osteoclastogenesis was also evaluated after monocytes were co-cultured with IL-17-prestimulated FLS. There was significant correlation between RANKL and IL-17 levels in RA synovial fluid. IL-17, IL-21, and IL-22 increased the expression of Rankl mRNA in RA FLS, and the IL-17-induced RANKL expression decreased by the inhibition of Act1, tumor necrosis factor receptor-associated factor $6, \mathrm{NF}-\kappa \mathrm{B}$, and activator protein-1. Th17 cytokines and IL-17prestimulated FLS induced osteoclastogenesis from monocytes in the absence of exogenous RANKL. The osteoclastic effect was reduced by inhibition of tumor necrosis factor- $\alpha$. Th17 cytokines have a dual effect on osteoclastogenesis in RA: direct induction of osteoclastogenesis from monocytes and up-regulation of RANKL production in RA FLS. This Th17 cytokine/RANKL axis could be a potential therapeutic target for bone destruction in RA. (Am J Pathol 2015, 185: 3011-3024; http:// dx.doi.org/10.1016/j.ajpath.2015.07.017)
\end{abstract}

Rheumatoid arthritis (RA) is a chronic inflammatory disease characterized by uncontrolled synovitis and subsequent destruction of cartilage and bone. Osteoclasts are detected in synovial tissues and in the eroded bone surfaces, suggesting that osteoclastic bone resorption is involved in the pathogenesis of RA. ${ }^{1,2}$

Type 17 helper $\mathrm{T}$ cells (Th17), which are defined by selective IL-17 secretion, are considered a distinct lineage of $\mathrm{CD}^{+}$helper $\mathrm{T}$ cells, which are regulated by Th1 and Th2 cytokines. $^{3-5}$ IL-17A is a dominant proinflammatory cytokine produced by type 17 helper $\mathrm{T}$ cells (Th17)., IL-21, IL-22, and IL-26 are also produced by Th17 cells. In RA, IL-17A induces the production of proinflammatory mediators, such as IL-1 and tumor necrosis factor (TNF)- $\alpha$ from synovial fibroblasts, macrophages, and chondrocytes. Levels of IL-17 produced by $\mathrm{CD}^{+}{ }^{+} \mathrm{T}$ cells in the synovium are significantly higher in patients with RA than in patients with osteoarthritis (OA). ${ }^{8,9}$ The major roles of IL-17 are to coordinate local inflammation through the up-regulation of proinflammatory and neutrophil-mobilizing cytokines and chemokines, including IL-6, granulocyte colonystimulating factor, TNF- $\alpha$, IL- $1 \beta$, CXCL1, chemokine (C-C motif) ligand 2 (monocyte chemoattractant protein1), CXCL2 (macrophage inflammatory protein-2), chemokine (C-C motif) ligand 7 (monocyte chemoattractant protein-3), and chemokine (C-C motif) ligand 20 (macrophage inflammatory protein-3A), as well as matrix

Supported by Research Fund of Seoul St.Mary's Hospital, The Catholic University of Korea, the National Research Foundation of Korea grant, and Korean Government grants NRF-2010-0024198 (K.W.K.), NRF2013R1A1A1008171 (H.R.K.), and NRF-2014R1A2A2A01007223 (S.H.L.).

K.-W.K. and H.-R.K. contributed equally to this work.

M.-L.C. and S.-H.L. contributed equally to this work as senior authors.

Disclosures: None declared. 
metalloproteases, and to enable activated $\mathrm{T}$ cells to penetrate the extracellular matrix. IL-17A also induces receptor activator of NF- $\kappa \mathrm{B}$ ligand (RANKL) expression by synovial fibroblasts and osteoblasts to drive bone erosion indirectly ${ }^{10}$ and to activate synovial macrophages to secrete TNF- $\alpha$ and IL- $1 \beta$, two known osteoclastogenic factors. ${ }^{11}$ Synovial macrophages can be differentiated into fully functional bone-resorbing osteoclasts, and Th17induced differentiation of synovial macrophages into osteoclasts represents an important cellular mechanism in bone destruction associated with RA. ${ }^{12,13}$

Act1 adaptor protein is required for the development of joint pathology in the collagen-induced arthritis (CIA) model. ${ }^{14}$ Act1 (alias CIKS) is an adaptor protein required for IL-17A signaling and has an expression level similar to that of the fibroblast growth factor/IL-17 receptor (SEFIR) domain. On IL-17 stimulation, Act1 is recruited to IL-17 receptors through its SEFIR domain and is required for IL-17-mediated expression of genes involved in inflammation. Interestingly, Act1 is also needed for IL-17-dependent mRNA stability. ${ }^{15}$ Although the contribution of IL-17 in osteoclastogenesis using cultures of human monocytes alone has been documented in earlier studies ${ }^{16}$ the intracellular signal transduction pathway for RANKL production and osteoclast differentiation by IL-17 remains uncertain.

Herein, we investigated the effect of Th17 cytokines on RANKL production in fibroblast-like synoviocytes (FLSs) and osteoclast differentiation from peripheral blood monocytes in RA, and we determined the signal transduction pathways mediating IL-17-induced osteoclastogenesis. We found that Th17 cytokines, especially IL-17, regulated osteoclastogenesis through both direct and indirect pathways. Indirectly, IL-17 induced RANKL production of RA FLS and, directly, it induced osteoclast differentiation from osteoclast precursors. Act1/TNF receptor-associated factor (TRAF) $6 / \mathrm{NF}-\kappa \mathrm{B}$ and activator protein (AP)-1 mediated IL-17-induced RANKL production and osteoclast differentiation.

\section{Materials and Methods}

\section{Patients}

Samples of RA synovium were isolated from seven patients with RA and five patients with OA (age range, 32 to 70 years; mean age, $56.6 \pm 4.7$ years), who were undergoing total knee replacement surgery. Synovial fluid was obtained from 19 RA patients who fulfilled the 1987 revised criteria of the American College of Rheumatology (formerly the American Rheumatism Association) ${ }^{17}$ and 19 patients who had symptomatic knee OA. Informed consent was obtained from all patients, and the experimental protocol was approved by the Konkuk University School of Medicine (Seoul, Republic of Korea) Human Research Ethics Committee.

\section{Isolation of FLS}

FLSs were isolated by enzymatic digestion of synovial tissues obtained from RA and OA patients undergoing total knee replacement surgery, as described previously. ${ }^{18}$

\section{Reagents}

Recombinant IL-17, IL-21, IL-22, receptor activator of NF$\kappa \mathrm{B}$ ligand (RANKL), and macrophage colony-stimulating factor (M-CSF) were purchased from R\&D Systems (Minneapolis, MN). Pyrrolidine dithiocarbamate, curcumin, and parthenolide were obtained from Sigma (St. Louis, MO). LY294002, SB203580, SP600125, and AG490 were obtained from Calbiochem (Schwalbach, Germany). TRAF6 inhibitor peptide was purchased from IMGENEX (San Diego, CA).

\section{Immunohistochemistry of RA Synovium}

Immunohistochemical staining for RANKL was performed with sections of synovium. Briefly, synovium was obtained from patients with RA and OA, fixed with $4 \%$ paraformaldehyde solution overnight at $4^{\circ} \mathrm{C}$, dehydrated with alcohol, washed, embedded in paraffin, and divided into sections (7 $\mu \mathrm{m}$ thick). Sections were depleted of endogenous peroxidase activity by adding methanolic hydrogen peroxide and blocked with normal serum for 30 minutes. After overnight incubation at $4^{\circ} \mathrm{C}$ with polyclonal anti-human RANKL antibody (Santa Cruz Biotechnology, Santa Cruz, CA), the samples were incubated with the secondary antibody, biotinylated anti-rabbit IgG, for 20 minutes, and then incubated with streptavidin-peroxidase complex (Vector, Peterborough, UK) for 1 hour, followed by incubation with 3,3'-diaminobenzidine (Dako, Glostrup, Denmark) for 5 minutes. The sections were counterstained with hematoxylin. Samples were finally imaged with an Olympus (Tokyo, Japan) photomicroscope.

\section{Enzyme-Linked Immunosorbent Assay}

In brief, a 96-well plate (Nunc; Sigma-Aldrich) was coated with $4 \mu \mathrm{g} / \mathrm{mL}$ monoclonal antibodies against soluble RANKL (sRANKL) and IL-17 (R\&D Systems) at $4^{\circ} \mathrm{C}$ overnight. After blocking with phosphate-buffered saline/ $1 \%$ bovine serum albumin $/ 0.05 \%$ Tween 20 (SigmaAldrich) for 2 hours at room temperature $\left(22^{\circ} \mathrm{C}\right.$ to $\left.25^{\circ} \mathrm{C}\right)$, test samples and the standard recombinant SRANKL and IL17 (R\&D Systems) were added to the 96-well plate and incubated at room temperature for 2 hours. Plates were washed four times with phosphate-buffered saline/Tween 20 , and then incubated with $500 \mathrm{ng} / \mathrm{mL}$ biotinylated mouse monoclonal antibodies against sRANKL and IL-17 (R\&D Systems) for 2 hours at room temperature. After washing, streptavidin-alkaline phosphate-horseradish peroxidase conjugate (Sigma) was incubated for 2 hours, then washed again and incubated with $1 \mathrm{mg} / \mathrm{mL} p$-nitrophenyl phosphate 
Table 1 Primers Used for PCR

\begin{tabular}{|c|c|c|}
\hline Primer name & Forward primer & Reverse primer \\
\hline Rankl & 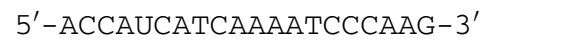 & 5'-CCCCAAAGTATGTTGCATCC-3' \\
\hline$\beta$-Actin & 5'-GGACTTCGAGCAAGAGATGG-3' & 5'-TGTGTTGGGGTACAGGTCTTTG-3' \\
\hline Act1 & 5'-GCATTCCTGTGGAGGTTGAT-3' & $5^{\prime}$-GTCTCCGGAGGAATTGTGAA-3' \\
\hline Traf6 & $5^{\prime}$-CCAATTTGCACATTCAG-3' & 5'-GGGCCAACATTCTCATGTGT-3' \\
\hline Traf3 & 5'-GGCCGTTTAAGCAGAAAGTG-3' & $5^{\prime}-\mathrm{ACAGTTTGGGCCACAAAGAC}-3^{\prime}$ \\
\hline Cathepsin $\mathrm{K}$ & 5'-TGAGGCTTCTCTTGGTGTCCATAC-3' & $5^{\prime}-$ AAAGGGTGTCATTACTGCGGG-3' \\
\hline Ctr & 5'-TGGTGCCAACCACTATCCATGC-3' & $5^{\prime}-\mathrm{CACAAGTGCCGCCATGACAG-3^{ \prime }}$ \\
\hline Mmp9 & 5'-CGCAGACATCGTCATCCAGT-3' & $5^{\prime}$-GGATTGGCCTTGGAAGATGA-3' \\
\hline
\end{tabular}

Act, actin related gene 1; Ctr, calcitonin receptor; Gapdh, glyceraldehyde-3-phosphate dehydrogenase; Mmp, matrix metalloprotease; Rankl, receptor

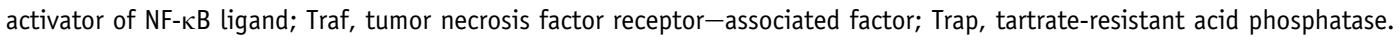

(Sigma) dissolved in diethanolamine (Sigma) to develop the color reaction. The reaction was stopped by the addition of 1 $\mathrm{mol} / \mathrm{L} \mathrm{NaOH}$, and the optical density of each well was read at $405 \mathrm{~nm}$. The lower limit of sRANKL and IL-17 detection was $10 \mathrm{pg} / \mathrm{mL}$. Recombinant human sRANKL and IL-17 diluted in culture medium were used as a calibration standard, ranging from 10 to $2000 \mathrm{pg} / \mathrm{mL}$. A standard curve was drawn by plotting optical density against the log of the concentration of recombinant cytokines, and used for determination of sRANKL and IL-17 concentrations in test samples.

\section{Dual-Luciferase Assay}

RANKL promoter activity was assessed by measurements of luciferase expression in RA FLS with transient transfection of appropriate cDNA constructs and luciferase reporter vectors (namely, pGL3-704) to 111. Another reporter plasmid, Renilla luciferase (Promega, Madison, WI), was cotransfected as an internal transfection control. RANKL transcription was evaluated with pGL3-RANKL-luc plasmid containing the luciferase gene under the control of the RANKL-inducible promoter. Transient transfection of RA FLS by FuGENE HD (Promega) was previously described. ${ }^{11}$ Briefly, cells were seeded in 6 -well plates at $2 \times 10^{5}$ cells per well 1 day before transfection. Transfection was performed according to the manufacturer's recommendations using $1 \mu \mathrm{g}$ of pGL3-RANKL reporter plasmids and $1 \mu \mathrm{g}$ of pRL-TK (promoter-Renilla luciferase reporter plasmid) control plasmid, 24 hours after transfection cells were stimulated or left unstimulated for 24 hours. After 24 hours, cells were lysed by $500 \mu \mathrm{L}$ of Passive Lysis Buffer $1 \times$ supplied by Promega. Luciferase assays were performed using the dualluciferase reporter assay kit (Promega).

\section{Real-Time PCR}

FLSs were stimulated with various concentrations of IL-17 $(0.1,1,10,20$, and $50 \mathrm{ng} / \mathrm{mL})$. For signal pathway analysis of RANKL, FLSs were incubated in the presence or absence of $10 \mu \mathrm{mol} / \mathrm{L}$ parthenolide, $10 \mu \mathrm{mol} / \mathrm{L}$ curcumin, $20 \mu \mathrm{mol} / \mathrm{L}$ Ly294002, $10 \mathrm{nmol} / \mathrm{L}$ SB203580, $1 \mu \mathrm{mol} / \mathrm{L}$ SP600125, or $50 \mu \mathrm{mol} / \mathrm{L}$ AG490 for 1 hour before the addition of IL-17. After incubation for 72 hours, mRNA was extracted using RNAzol B (Biotex Laboratories, Houston, TX), according to the manufacturer's instructions. Reverse transcription of $2 \mu \mathrm{g}$ of total mRNA was performed at $42^{\circ} \mathrm{C}$ using the Superscript reverse transcription system (Takara, Shiga, Japan). PCR was performed in a $20-\mu \mathrm{L}$ final volume in capillary tubes in a LightCycler instrument (Roche Diagnostics, Mannheim, Germany). The reaction mixture contained $2 \mu \mathrm{L}$ of LightCycler FastStart DNA MasterMix for SYBR Green I (Roche Diagnostics), $0.5 \mu \mathrm{mol} / \mathrm{L}$ of each primer, $4 \mathrm{mmol} / \mathrm{L} \mathrm{MgCl}_{2}$, and $2 \mu \mathrm{L}$ of template DNA. All capillaries were sealed, centrifuged at $500 \mathrm{X} g$ for 5 seconds, and then amplified in a LightCycler instrument, with activation of polymerase $\left(95^{\circ} \mathrm{C}\right.$ for 10 minutes), followed by 45 cycles of 10 seconds at $95^{\circ} \mathrm{C}, 10$ seconds at $60^{\circ} \mathrm{C}(\beta$-actin $)$ and at $59^{\circ} \mathrm{C}($ Rankl $)$, and 10 seconds at $72^{\circ} \mathrm{C}$. The temperature transition rate was $20^{\circ} \mathrm{C} /$ second for all steps. The double-stranded PCR product was measured during the $72{ }^{\circ} \mathrm{C}$ extension step by detection of fluorescence associated with the binding of SYBR Green I to the product. Fluorescence curves were analyzed with LightCycler software version 3.0 (Roche Diagnostics). The LightCycler was used to quantify Rankl mRNA. The relative expression level of each sample was calculated as the level of Rankl normalized to the endogenously expressed $\beta$-actin gene. Melting curve analysis was performed immediately after the amplification protocol under the following conditions: 0 second (hold time) at $95^{\circ} \mathrm{C}, 15$ seconds at $71^{\circ} \mathrm{C}$, and 0 second (hold time) at $95^{\circ} \mathrm{C}$. The rate of temperature change was $20^{\circ} \mathrm{C} /$ second, except for $0.1^{\circ} \mathrm{C}$ / second in the final step. The melting peak generated represented the amount of specific amplified product. The crossing point was defined as the maximum of the second derivative from the fluorescence curve. Negative controls were also included and contained all of the elements of the reaction mixture except template DNA. All samples were processed in duplicate. 

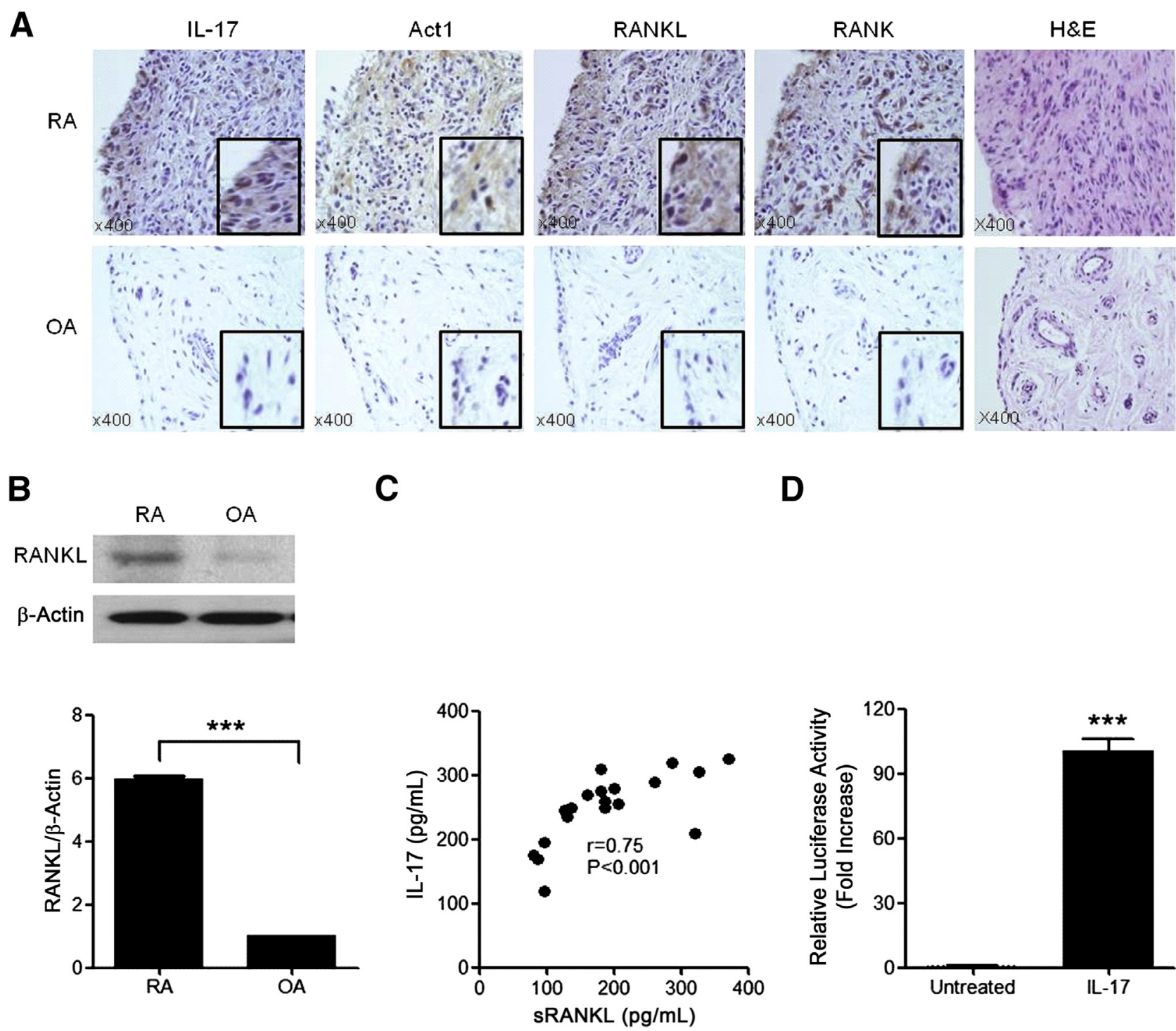

Figure 1 Expression of IL-17 and receptor activator of NF-KB ligand (RANKL) in synovial tissues and fibroblast-like synoviocytes (FLSs) of rheumatoid arthritis (RA) patients. A: Immunohistochemical staining of IL-17, Act1, RANKL, and RANK in the synovial tissues. There is more intense expression of IL-17, Act1, RANKL, and RANK in RA synovial tissues compared with osteoarthritis (OA) synovial tissues. B: RA FLS, but not OA FLS, constitutively expresses RANKL protein, which was determined by Western blot analysis. The amount of protein expression was normalized by $\beta$-actin. C: Synovial fluid levels of IL-17 and soluble RANKL (sRANKL) in RA patients were measured using an enzyme-linked immunosorbent assay. D: RA FLSs were transfected with $1 \mu \mathrm{g}$ of pGL3-RANKL reporter plasmids and $1 \mu \mathrm{g}$ of pRL-TK (promoter-Renilla luciferase reporter plasmid) control plasmid. Both firefly and renilla luminescences were measured after 24 hours' incubation. Data represent means \pm SEM of three independent experiments (B and D). $n=19(\mathbf{C}) .{ }^{* *} P<0.005$. Original magnification, $\times 400(\mathbf{A})$. $\mathrm{H} \& \mathrm{E}$, hematoxylin and eosin.

\section{RT-PCR}

FLSs were incubated with various concentrations of IL-17, IL-21, or IL-22. After incubation for 72 hours, mRNA was extracted using RNAzol B (Biotex Laboratories), according to the manufacturer's instructions. Reverse transcription of $2 \mu \mathrm{g}$ total mRNA was performed at $42^{\circ} \mathrm{C}$ using the Superscript reverse transcription system (Takara). PCR amplification of cDNA aliquots was performed by adding 2.5 $\mathrm{mmol} / \mathrm{L}$ dNTPs, $2.5 \mathrm{U}$ Taq DNA polymerase (Takara), and $0.25 \mu \mathrm{mol} / \mathrm{L}$ of sense and antisense primers. The reaction was performed in PCR buffer $\left(1.5 \mathrm{mmol} / \mathrm{L} \mathrm{MgCl}_{2}, 50\right.$ $\mathrm{mmol} / \mathrm{L} \mathrm{KCl}$, and $10 \mathrm{mmol} / \mathrm{L}$ Tris- $\mathrm{HCl}, \mathrm{pH} 8.3$ ) in a total volume of $25 \mu \mathrm{L}$. The following sense and antisense primers for each molecule were used $\left(5^{\prime} \rightarrow 3^{\prime}\right)$ (Table 1$)$. Reactions were processed in a DNA thermal cycler (PerkinElmer Cetus, Wellesley, MA). PCR products were run on a $2 \%$ agarose gel and stained with ethidium bromide. Results are expressed as the ratio of Rankl (forward primer, 5' ACCAGCATCAAAATCCCAAG- $3^{\prime}$; reverse primer, 5' CCCCAAAGTATGTTGCATCC-3') and PCR product relative to Gapdh (forward primer, 5'-CGATGCTGGGCGTGAGTAC-3'; reverse primer, 5'-CGTTCAGCTCAGGGATGACC-3'). 


\section{Western Blot Analysis}

FLSs were incubated with IL-17. After incubation for 72 hours, whole-cell lysates were prepared from approximately $2 \times 10^{5}$ cells by homogenization in the lysis buffer, and centrifuged at $19,320 \times g$ for 15 minutes. The protein concentration in the supernatant was determined using the Bradford method (BioRad, Hercules, CA). Protein samples were separated onto $10 \%$ SDS-PAGE, and transferred to a nitrocellulose membrane (Amersham Pharmacia Biotech, Uppsala, Sweden). For western hybridization, the membrane was preincubated with $0.5 \%$ skim milk in $0.1 \%$ Tween 20 in Tris-buffered saline at room temperature for 2 hours. The primary antibody to RANKL (R\&D Systems), diluted $1: 1000$ in $5 \%$ bovine serum albumin $-0.1 \%$ Tween 20/Tris-buffered saline, was added and incubated for overnight at $4^{\circ} \mathrm{C}$. The membrane was washed four times with $0.1 \%$ Tween 20 in Tris-buffered saline, and horseradish peroxidase-conjugated secondary antibody was added and incubated for 1 hour at room temperature. After $0.1 \%$ Tween 20 in Tris-buffered saline washing, hybridized bands were detected using the electrochemiluminescence detection kit and Hyperfilm-enhanced chemiluminescence (ECL) reagents (Amersham Pharmacia Biotech, Piscataway, NJ).

\section{Magnetofection of Oligonucleotides}

siRNAs were transfected using magnetofection, as described previously, ${ }^{19,20}$ and the assays were performed 24 hours later. Act1 and control were purchased from Dharmacon Inc. (Chicago, IL).

\section{Isolation of Peripheral Blood Monocytes}

Peripheral blood mononuclear cells were separated by FicollHypaque (Sigma Chemicals, Poole, Dorset, UK) density gradient centrifugation from the buffy coats obtained from healthy volunteers. The cells were washed three times with sterile phosphate-buffered saline and resuspended in RPMI 1640 medium (Life Technologies, Grand Island, NY) supplemented with $10 \%$ fetal bovine serum, $2 \mathrm{mmol} / \mathrm{L}$ L-glutamine, and $1 \%$ penicillin-streptomycin, henceforth called complete medium. Freshly isolated peripheral blood mononuclear cells were incubated at $37^{\circ} \mathrm{C}$ in complete medium and allowed to adhere for 45 minutes. The nonadherent cells were removed, and the adherent cells were washed with sterile phosphate-buffered saline, harvested with a rubber policeman, and stained with the monocyte-specific anti-CD14 monoclonal antibody to assess the purity of the preparation. Of the isolated cells, $90 \%$ expressed CD14. The osteoclast precursors were prepared using the monocytes-enriched fraction from the peripheral blood.

\section{0steoclast Differentiation}

RA synovial fibroblasts were pretreated with $10 \mathrm{ng} / \mathrm{mL}$ recombinant human (rh)IL-17 for 3 days, after which monocytes were added to each well along with the
A

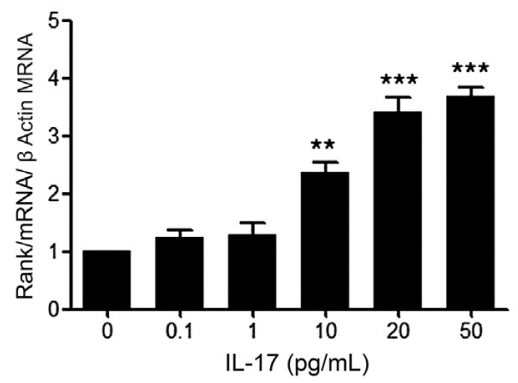

C

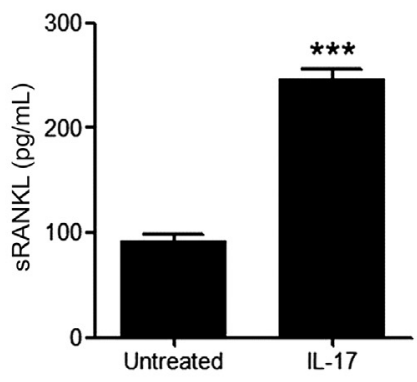

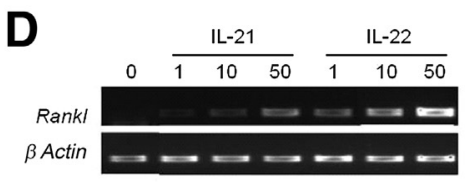
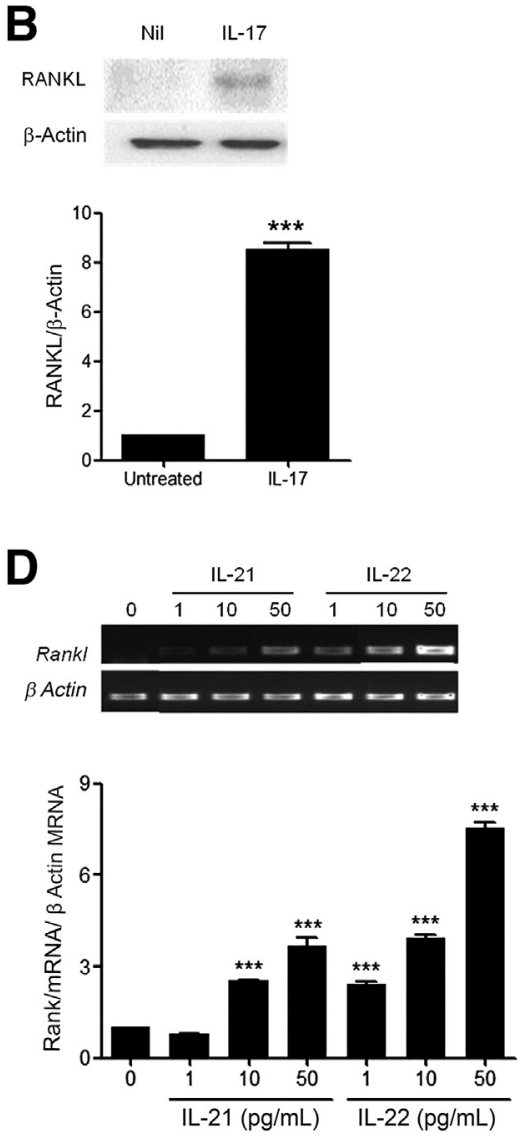

Figure 2 The expression of receptor activator of NF-KB ligand (RANKL) is up-regulated by type 17 helper T-cell cytokines in rheumatoid arthritis (RA) fibroblast-like synoviocytes (FLSs). A: RA FLSs were cultured for 72 hours with 0 to $50 \mathrm{ng} / \mathrm{mL}$ IL17, and Rankl mRNA expression was determined using real-time PCR. The data were expressed as the relative mRNA expression of Rankl/ $\beta$-actin. B: RA FLSs were cultured with $50 \mathrm{ng} / \mathrm{mL}$ of IL-17 for 72 hours, and the expression of RANKL protein in cell lysates was determined using Western blot analysis. The amount of RANKL expression was normalized by $\beta$-actin. C: RA FLSs were cultured with $50 \mathrm{ng} / \mathrm{mL}$ of IL-17 for 72 hours, and the RANKL concentration of cultured media was determined using an enzyme-linked immunosorbent assay. D: RA FLSs were cultured for 72 hours with IL-21 or IL-22, and Rankl mRNA expression was determined using real-time PCR. The data were expressed as the relative mRNA expression of Rankl/ $\beta$-actin. The figures are representative of three independent experiments. Data represent means \pm SEM of three independent experiments. $n=3$ (D). ${ }^{* *} P<0.01,{ }^{* * *} P<0.005$ versus untreated (0). sRANKL, soluble RANKL. 
different signal inhibitors, including $20 \mu \mathrm{mol} / \mathrm{L}$ LY294002, $50 \mu \mathrm{mol} / \mathrm{L}$ AG490, $10 \mu \mathrm{mol} / \mathrm{L}$ SB203580, 10 $\mu \mathrm{mol} / \mathrm{L}$ parthenolide, or $10 \mu \mathrm{mol} / \mathrm{L}$ curcumin. As described above, the isolated human monocytes $\left(5 \times 10^{4}\right.$ cells per well) were added to the stimulated fibroblasts with fresh media. The cells were co-cultured for 3 weeks in $\alpha$-minimal essential medium and $10 \%$ heat-inactivated fetal bovine serum in the presence of $25 \mathrm{ng} / \mathrm{mL}$ of $\mathrm{rhM}$ CSF. The medium was changed on day 3 and then every other day. The addition of rhRANKL protein, prepared as described previously, ${ }^{21}$ was used as the positive control. On day 21, tartrate-resistant acid phosphatase (TRAP)-positive cells were identified using a leukocyte acid phosphatase kit, according to the manufacturer's protocol (Sigma). ${ }^{22}$

\section{Bone Resorption Assay}

We performed an in vitro resorption pit assay using a bone resorption assay kit (Cosmo Bio Co., Ltd., Tokyo, Japan). Monocytes were cultured on a bone-coating plate with $\mathrm{M}$ CSF in the presence or absence of various concentrations of Th17 cytokines (IL-17, IL-21, and IL-22) for 14 days. The cells were removed from the bone-coating plate by wiping the surface. The numbers of pit formed by bone resorption on the plate were counted.

\section{Statistical Analysis}

Data are expressed as the means \pm SEM. Statistical analysis was performed using one-way analysis of variance, followed by the Dunnett's multiple-comparison test for comparison of more than two experimental groups. $P<0.05$ was considered statistically significant.

\section{Results}

\section{Expression of IL-17, Act1, RANKL, and RANK in RA Synovial Tissues}

IL-17, Act1, RANKL, and RANK, identified by immunohistochemical staining, were expressed intensively in RA synovial tissues, compared with OA synovium (Figure 1A). Specifically, IL-17, Act1, RANKL, and RANK were abundantly expressed in the lining and sublining of RA synovium, whereas their expression was faint in OA synovium. The basal expression of RANKL protein was higher in RA FLS than in OA FLS, as determined by Western blot analysis (Figure 1B).

Synovial fluid IL-17 (RA versus OA, $254.7 \pm 49.9$ versus $70.1 \pm 98.2 \mathrm{pg} / \mathrm{mL} ; P<0.001$ ) and sRANKL (RA versus OA, $280.4 \pm 199.9$ versus $215.6 \pm 105.0 \mathrm{pg} / \mathrm{mL} ; P<0.01$ ) levels were much higher in 19 RA patients than in 19 OA patients. Synovial sRANKL and synovial IL-17 levels were
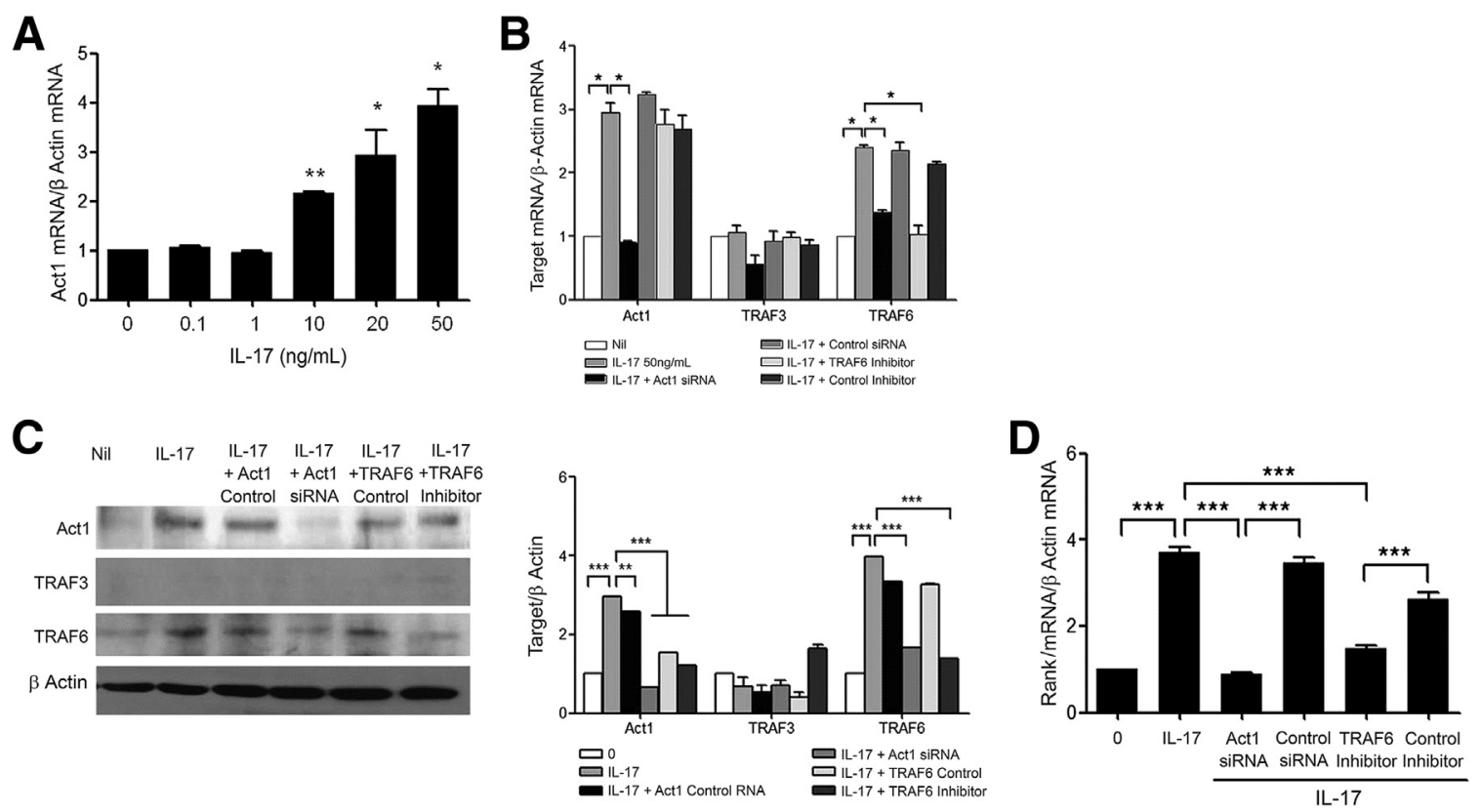

Figure 3 The IL-17-induced receptor activator of NF-KB ligand (RANKL) expression is mediated through Act1 and tumor necrosis factor receptor-associated factor (TRAF) 6 pathways. A: Rheumatoid arthritis (RA) fibroblast-like synoviocytes (FLSs) were cultured for 72 hours with IL17, and the expression of Act1 was determined using real-time PCR. The data were expressed as the relative mRNA expression of Act1/ $\beta$-actin. B: RA FLSs were cultured with $50 \mathrm{ng} / \mathrm{mL}$ of IL-17 and Act1 siRNA or TRAF6 inhibitor peptide for 72 hours, and the mRNA expression of Act1, Traf6, and Traf3 was determined by real-time PCR. The amount of target gene expression was normalized by $\beta$-actin. Data are shown as the relative mRNA expression of target/ $\beta$-actin. C: The protein expression of Act1 and TRAF6 by IL-17 was determined by Western blot analysis. The data are shown as target protein/ $\beta$-actin ratio. D: IL-17-induced Rankl expression in RA FLS, which was determined by real-time PCR. The data were expressed as the relative mRNA expression of Rankl/ $\beta$-actin. Data represent means \pm SEM of three independent experiments $(\mathbf{A}-\mathbf{D})$. ${ }^{*} P<0.05$, ${ }^{* *} P<0.01$, and $* * * P<0.005$. 
A

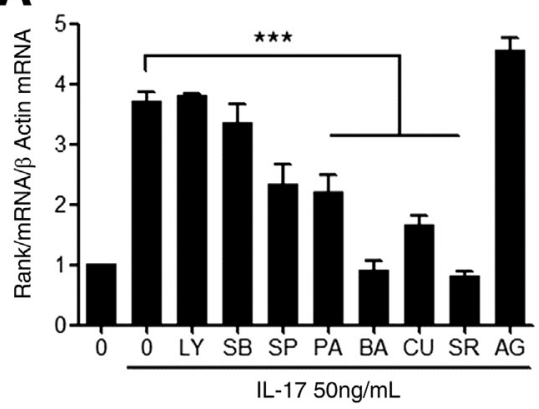

C
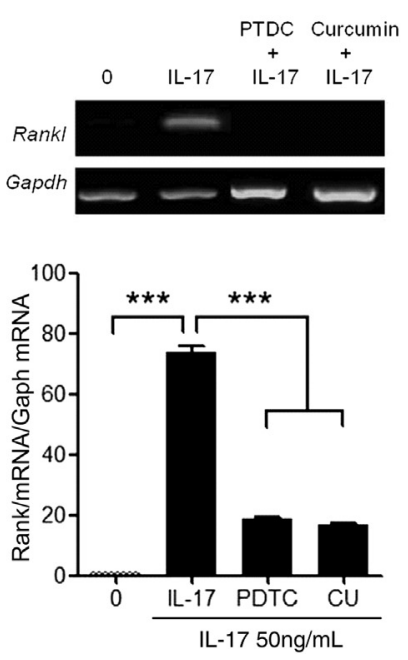

B

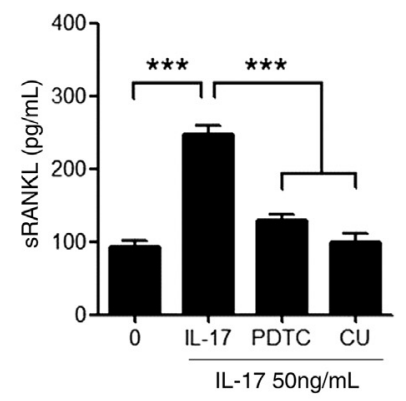

D
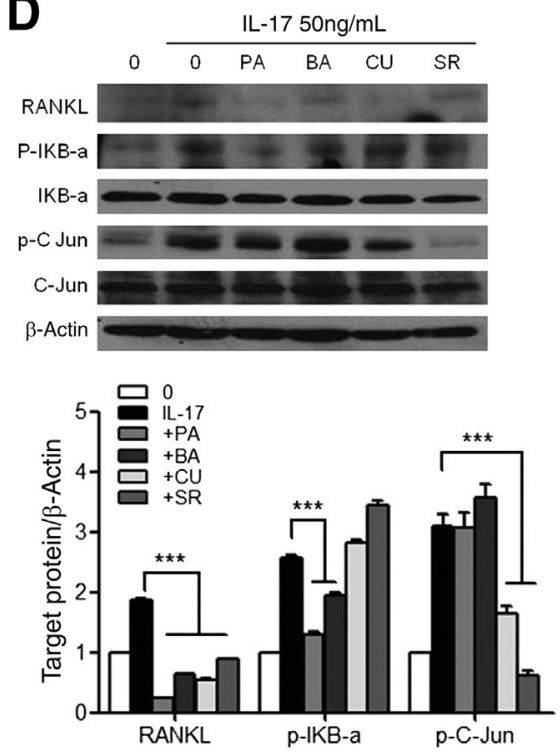

Figure 4 Downstream signal pathways mediating IL-17-induced receptor activator of NF- $\mathrm{KB}$ ligand (RANKL) expression in rheumatoid arthritis (RA) fibroblast-like synoviocytes (FLSs). A: RA FLSs were pretreated with $20 \mu \mathrm{mol} / \mathrm{L}$ of LY294002 (LY), $10 \mathrm{nmol} / \mathrm{L}$ of SB203580 (SB), $1 \mu \mathrm{mol} / \mathrm{L}$ of SP600125 (SP), $1 \mu \mathrm{mol} / \mathrm{L}$ of AG490 (AG), $10 \mu \mathrm{mol} /$ $L$ of parthenolide (PA), $0.1 \mu \mathrm{mol} / \mathrm{L}$ of BAY11-7085 (BA), $10 \mu \mathrm{mol} / \mathrm{L}$ of curcumin (CU), or $1 \mu \mathrm{mol} / \mathrm{L}$ of SR11302 (SR) for 1 hour, and then they were cultured with $50 \mathrm{ng} / \mathrm{mL}$ of IL-17 for 72 hours. Rankl mRNA was extracted and quantified using quantitative real-time PCR. The amount of Rankl expression was normalized by $\beta$-actin. The data were expressed as the relative mRNA expression of Rankl/ $\beta$-actin. B: RA FLSs were cultured with IL-17 and $10 \mu \mathrm{mol} / \mathrm{L}$ of pyrrolidine dithiocarbamate (PDTC) or $10 \mu \mathrm{mol} / \mathrm{L}$ of curcumin, and then the RANKL concentration was measured in the cultured media using enzyme-linked immunosorbent assay. C: RA FLSs were pretreated with PDTC or curcumin for 1 hour, and then cultured with $50 \mathrm{ng} / \mathrm{mL}$ of IL17 for 72 hours. Rankl mRNA was extracted and quantified using RT-PCR. The data were expressed as the relative mRNA expression of Rankl/ $\beta$-actin. D: RA FLSs were cultured with $50 \mathrm{ng} / \mathrm{mL}$ of IL-17 and then the phosphorylation of I $B \alpha$ and $c-J u n$ was assessed in cell lysates using Western blot analysis. The data were expressed as the relative protein expression of targets/ $\beta$-actin. Data represent the means \pm SEM of three independent experiments (A-D). ${ }^{* * * P}<0.005$. sRANKL, soluble RANKL. correlated in 19 RA patients $\left(r^{2}=0.48, P<0.05\right)$ (Figure 1C). The patients included 4 men and 15 women, with a mean age of $50.4 \pm 1.5$ years (range, 23 to 77 years) and a mean disease duration of $71.5 \pm 8.2$ months (range, 3 to 240 months).

To investigate RANKL-promoting activity by IL-17, we performed a pGL3-luciferase reporter gene assay using pGL3-RANKL Luc and Renilla Luc transfection. IL-17 increased RANKL activity by 105 -fold compared with the unstimulated condition (Figure 1D).

\section{Th17 Cytokines Stimulate RA FLS to Express and Produce RANKL}

After RA FLSs were stimulated with various dosages of IL17, the expression of Rankl mRNA was determined using real-time PCR. IL-17 induced the expression of Rankl mRNA in a dose-dependent manner (Figure 2A). No additive effect was observed on RANKL expression after stimulation with a combination of IL-17 and other proinflammatory cytokines, such as TNF- $\alpha$ and IL-1 $\beta$ (data not shown). Neither a cytotoxic effect nor a proliferative effect was observed on RA FLS at the experimental dosages of IL17 (data not shown). The expression and production of
RANKL protein were also increased with IL-17 stimulation in RA FLS, as determined by Western blot analysis (Figure 2B) and enzyme-linked immunosorbent assay in culture media (Figure 2C). After RA FLSs were stimulated with other Th17 cytokines, IL-21 and IL-22, the expression of Rankl mRNA was determined using RT-PCR. IL-21 and IL-22 also increased the expression of Rankl mRNA in a dose-dependent manner (Figure 2D).

\section{Act1 and TRAF6 Mediate IL-17-Induced RANKL Expression}

In a previous study, IL-17 was found to increase Act1 activity in human fibroblasts, the biological function of which is TRAF6 dependent. ${ }^{23}$ To determine the intracellular pathways of IL-17-induced RANKL expression in RA FLS, we explored the regulatory effect of IL-17 on Act1 activation. IL-17 increased the expression of Act 1 mRNA in RA FLS in a dose-dependent manner (Figure 3A). Then, by using Actl siRNA, the expression of TRAF6 and TRAF3 was observed. Act1 siRNA blocked both IL-17-induced Act1 and TRAF6 expression, and TRAF6 inhibitor peptide decreased TRAF6 expression (Figure 3, B and C). IL17-induced Rankl expression was significantly decreased 

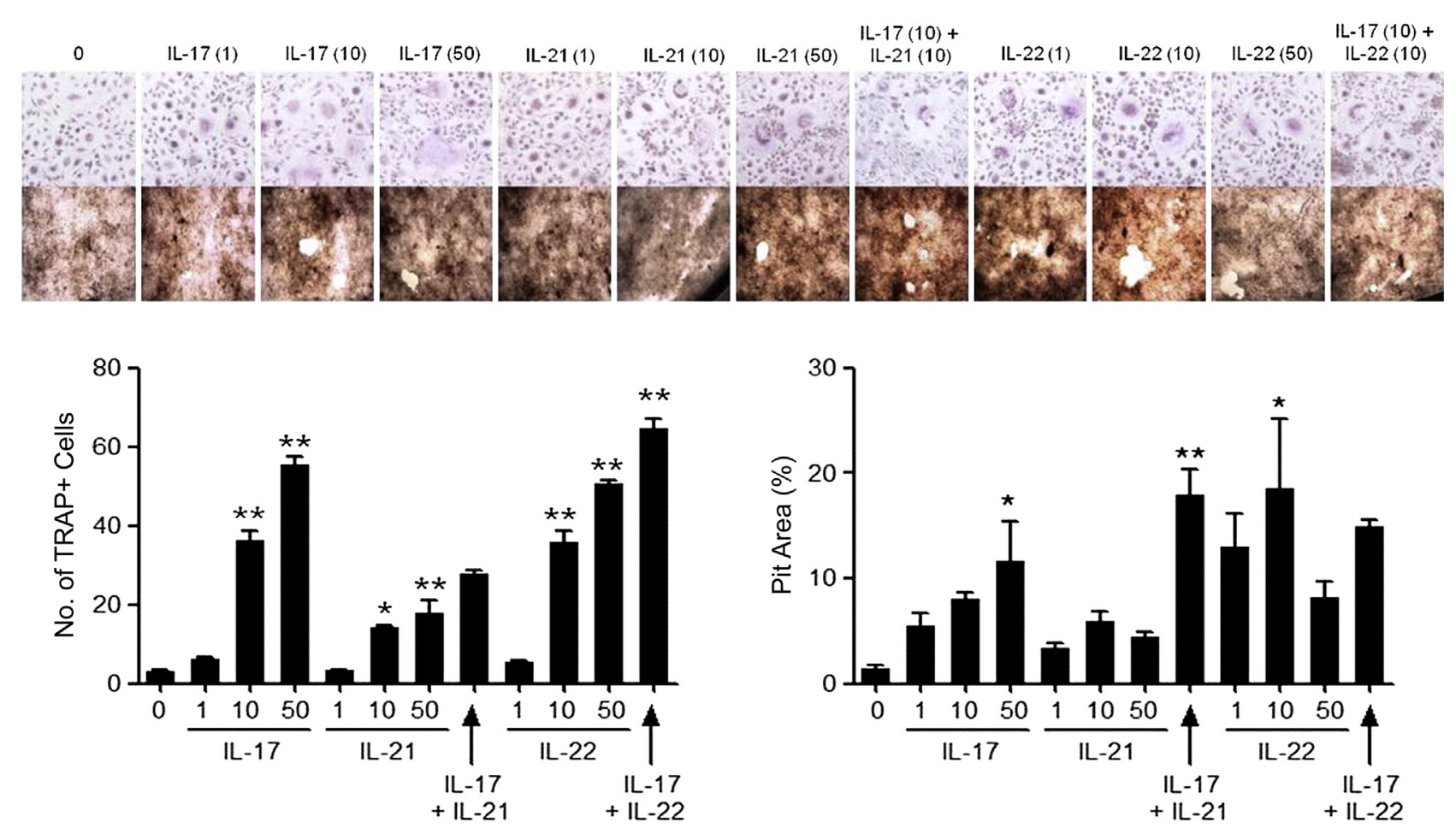

Figure 5 Type 17 helper T-cell (Th17) cytokines differentiate peripheral blood monocytes into osteoclasts. Human peripheral blood CD14 ${ }^{+}$monocytes were isolated and cultured with $25 \mathrm{ng} / \mathrm{mL}$ of macrophage colony-stimulating factor and Th17 cytokines, IL-17, IL-21, or IL-22, and the osteoclast differentiation was determined by counting tartrate-resistant acid phosphatase (TRAP) ${ }^{+}$multinucleated cells and bone resorption assay. The cultures were stained with TRAP, and the number of $\mathrm{TRAP}^{+}$multinucleated cells was counted. The figures are representative of three independent experiments. ${ }^{*} P<0.05,{ }^{*} P<0.01$.

with Act1 and TRAF6 inhibition (Figure 3D). This result suggests that IL-17-induced RANKL expression is mediated through an Act1 and TRAF6 pathway.

\section{IL-17-Induced RANKL Expression Is Mediated by NF- $\kappa B$ and AP-1 Signaling Pathways}

To determine the downstream signaling pathways mediating the up-regulation of RANKL by IL-17, we used $20 \mu \mathrm{mol} / \mathrm{L}$ of $\mathrm{LY} 294002,10 \mu \mathrm{mol} / \mathrm{L}$ of SB203580, $1 \mu \mathrm{mol} / \mathrm{L}$ of SP600125, $50 \mu \mathrm{mol} / \mathrm{L}$ of $\mathrm{AG} 490,10 \mu \mathrm{mol} / \mathrm{L}$ of parthenolide, and 0.1 $\mu \mathrm{mol} / \mathrm{L}$ of BAY11-7085, $10 \mu \mathrm{mol} / \mathrm{L}$ of curcumin, and $1 \mu \mathrm{mol} /$ L of SR11302 that antagonize the activation of phosphatidylinositol 3-kinase, p38 mitogen-activated protein kinase (MAPK), c-Jun N-terminal kinase, STAT3, NF-кB, and AP-1, respectively. After RA FLSs were cultured with IL-17 and the various signal inhibitors, expression of Rankl mRNA by FLS was evaluated by RT-PCR and real-time PCR. IL-17-induced Rankl expression was significantly decreased after inhibiting NF- $\kappa$ B and AP-1 activities (Figure 4A). However, the blockage of phosphatidylinositol 3-kinase, p38 MAPK, c-Jun $\mathrm{N}$-terminal kinase, and STAT3 showed no effect on IL17-induced RANKL expression. The expression of RANKL protein in RA FLS and the production of RANKL in culture were also decreased by inhibition of NF- $\mathrm{KB}$ and AP-1 activities (Figure 4, B and C). These results suggest that IL-17 regulates RANKL expression in RA FLS via NF- $\kappa \mathrm{B}-$ and AP-1-mediated pathways. To confirm the activation of these intracellular signaling molecules by IL-17 in RA FLS, the phosphorylation of I $\kappa \mathrm{B}-\alpha$ and c-Jun was evaluated by Western blot analysis. The activation of NF- $\kappa \mathrm{B}$ was analyzed by monitoring the phosphorylation of $\mathrm{I} \kappa \mathrm{B}-\alpha$, and the activation of AP-1 was analyzed by monitoring the phosphorylation of cJun. IL-17 increased the phosphorylation of I $\mathrm{B}-\alpha$ and c-Jun in RA FLS, and concomitantly increased the production of RANKL, whereas the total protein levels of I $\mathrm{B} \mathrm{B}-\alpha$ and c-Jun remained unchanged (Figure 4D).

\section{The Effect of Th17 Family Cytokines on Osteoclast Differentiation from Monocytes}

Human peripheral blood monocytes can differentiate into TRAP-positive multinucleated osteoclasts (OCs) in the presence of RANKL and M-CSF. ${ }^{10}$ To evaluate whether Th17 cytokines also have a role in the differentiation into OCs, human monocytes isolated from peripheral blood were cultured with IL-17, IL-21, IL-22, and M-CSF in the absence of exogenous RANKL. Under the effects of IL-17, IL-21, IL-22, and M-CSF, TRAP-positive multinucleated cells (ie, OCs) differentiated from monocytes $(P<0.05)$. However, no significant additive effect of IL-17 with other Th17 cytokines was observed (Figure 5).

For determining the mediation of RANKL and TNF- $\alpha$ in the IL-17-induced osteoclastogenesis, after neutralization of RANKL and TNF- $\alpha$, the osteoclastogenesis was assessed. RANKL and TNF- $\alpha$ induced osteoclastogenesis 


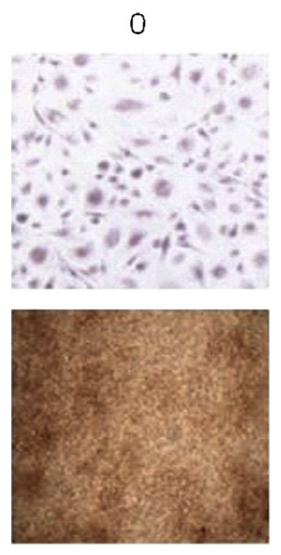

RANKL
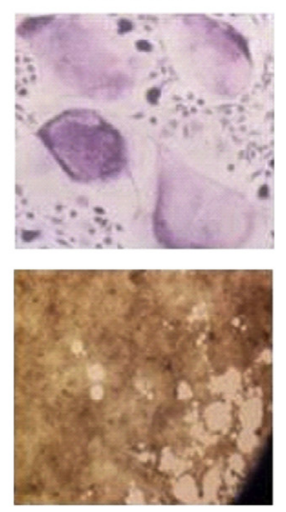

TNF- $\alpha$
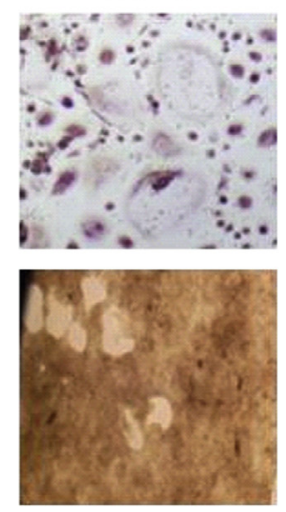

IL-17
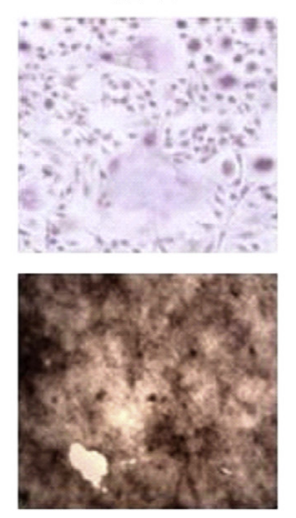

Anti-RANKL

$+$

IL-17
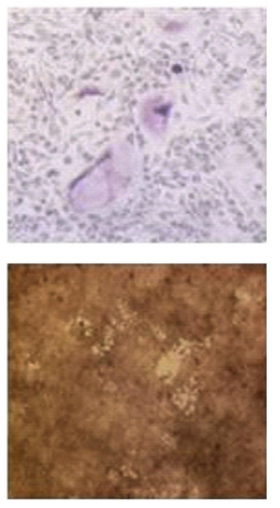

Anti-TNF- $\alpha$

$+$
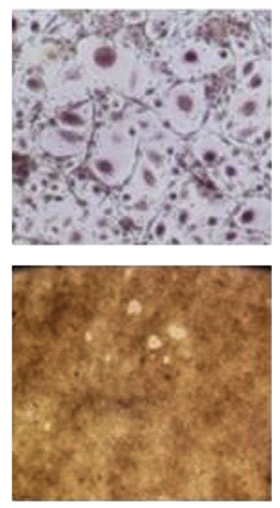
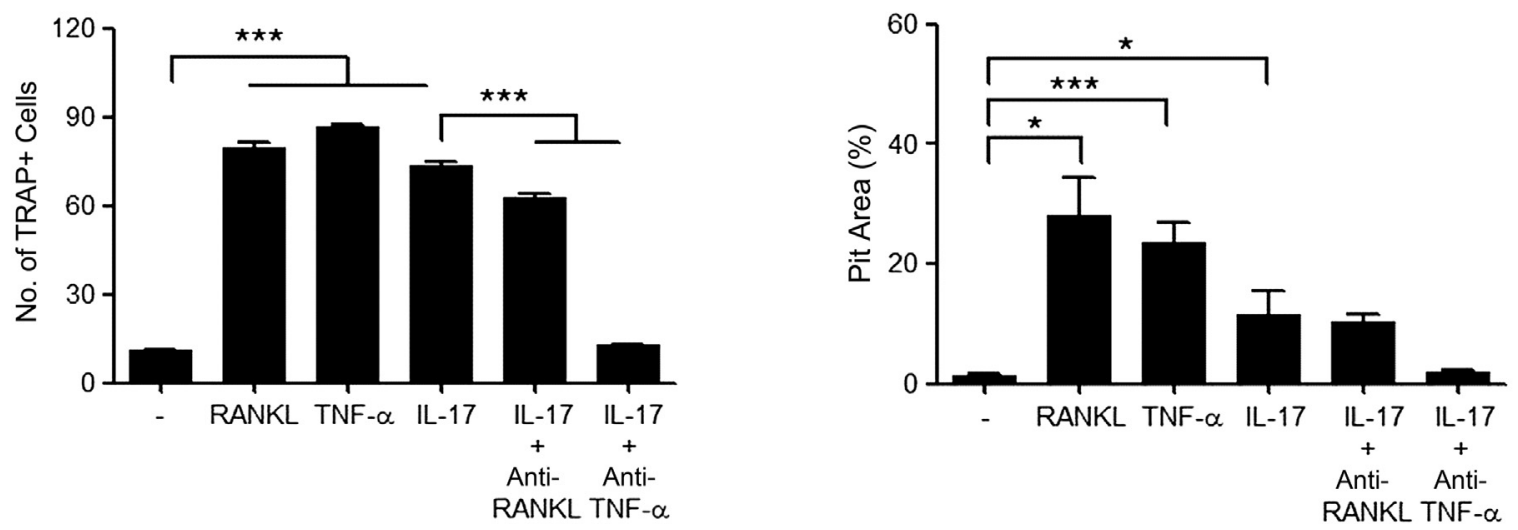

Figure 6 Type 17 helper T-cell (Th17) cytokines differentiate monocytes into osteoclasts without exogenous receptor activator of NF- $\kappa B$ ligand (RANKL). Peripheral blood CD14 ${ }^{+}$monocytes were cultured with $30 \mathrm{ng} / \mathrm{mL}$ RANKL, $10 \mathrm{ng} / \mathrm{mL}$ tumor necrosis factor (TNF)- $\alpha$, or $50 \mathrm{ng} / \mathrm{mL} \mathrm{IL}-17 \mathrm{in}$ the presence of macrophage colony-stimulating factor. Monocytes were cultured with $10 \mathrm{ng} / \mathrm{mL}$ anti-TNF or anti-RANKL in the presence of IL-17 and M-CSF. The figures are representative of three independent experiments. ${ }^{*} P<0.05,{ }^{* *} P<0.005$.

with a similar effect of IL-17, and the inhibition of RANKL and TNF- $\alpha$ reduced the IL-17-induced osteoclastogenesis. A bone-resorbing assay showed that the neutralization of TNF- $\alpha$ decreased IL-17-induced bone-resorbing activity, but the effect was not statistically significant (Figure 6).

To analyze intracellular signaling pathways mediating IL17-induced OC differentiation, monocytes were cultured with IL-17 and different signal inhibitors. Adhesion of monocytes and differentiation into TRAP-positive OCs were significantly decreased after culture with p38 MAPK, NF- $\kappa$ B, and AP-1 inhibitors $(P<0.05)$ (Figure 7A). We performed an in vitro resorption pit assay using a bone resorption assay kit (Cosmo Bio Co, Ltd). Many resorption pits were generated in wells with Th17 cytokine-treated cells. In contrast, curcumin treatment inhibited formation of resorption pits in the IL17-treated cells. The number of resorbed pits revealed $>50 \%$ inhibition by $10 \mu \mathrm{mol} / \mathrm{L}$ curcumin. Together, these results suggest that curcumin, an AP-1 inhibitor, exerts an antiosteoclastogenic effect on bone marrow-derived precursor cells, which results in reduced bone resorption. The expression of osteoclast markers, such as Trap, Rank, Ctsk, Caler, and Mmp9, was also decreased after treatment with p38 MAPK,
NF- $\kappa \mathrm{B}$, and AP-1 inhibitors $(P<0.05)$ (Figure 7B). This result suggests that IL-17 differentiates osteoclast precursors into mature osteoclasts in the absence of RANKL or osteoblasts and that this osteoclastogenesis is mediated by $\mathrm{p} 38$ MAPK, NF-KB, and AP-1 pathways.

\section{RA FLSs Pre-Exposed to IL-17 Promote 0steoclast Differentiation}

RA FLSs can induce osteoclast differentiation when they are co-cultured with peripheral blood monocytes. In the clinical scenario, RA FLSs might be exposed and activated by many proinflammatory cytokines before they contact osteoclast precursors. We studied peripheral blood CD14 ${ }^{+}$ monocytes that were co-cultured with TNF- $\alpha-$ or IL17-prestimulated RA FLS and M-CSF. Without addition of exogenous RANKL, the monocytes differentiated into multinucleated TRAP-positive multinucleated cells, osteoclasts, in contrast to that observed in co-culture with unstimulated FLSs $(P<0.05)$. The osteoclast differentiation culturing with IL-17-stimulated RA FLS was decreased with the inhibition of osteoprotegerin and TNF- $\alpha$ (Figure 8). 
A
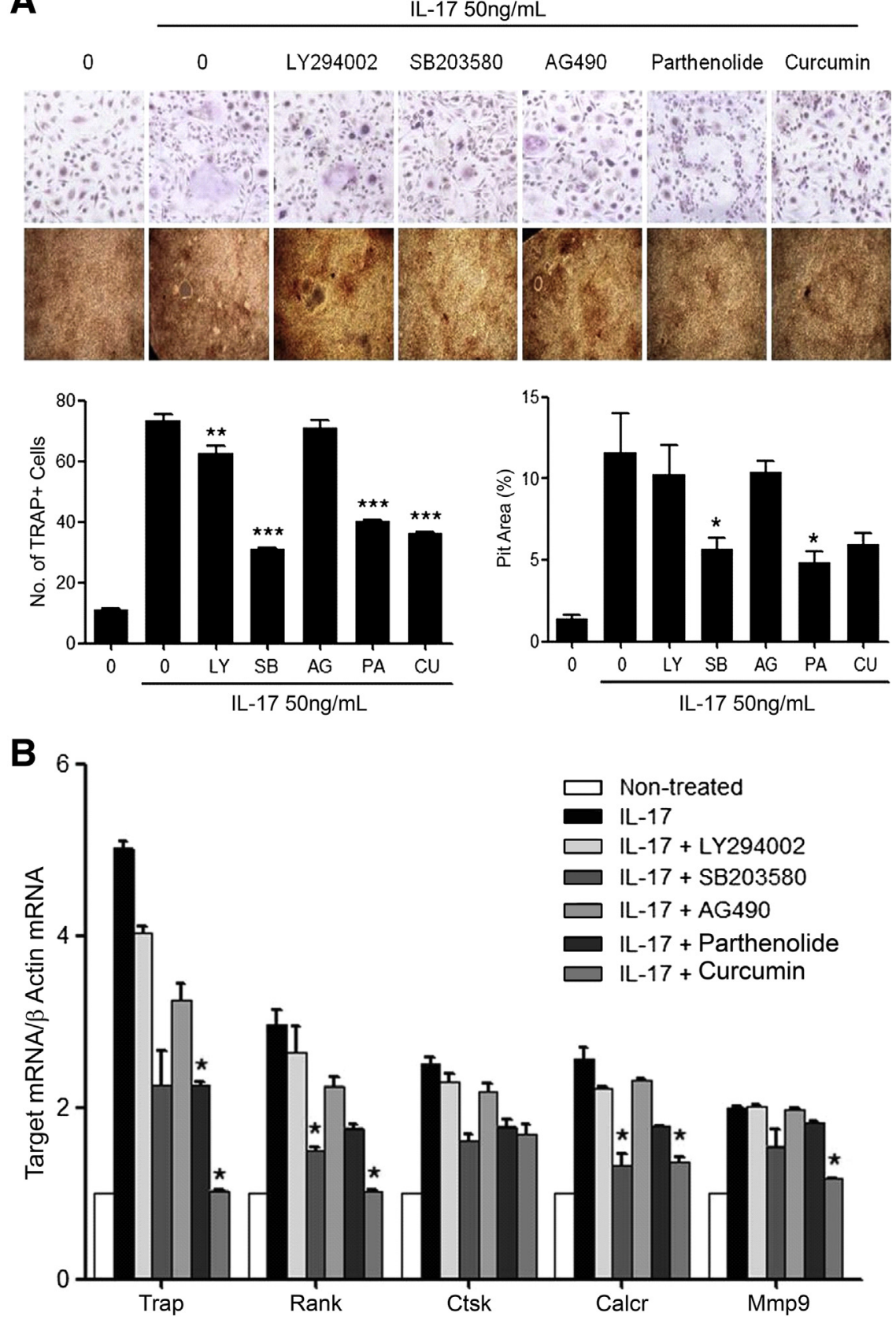

Figure 7 Intracellular signaling pathways involved in type 17 helper T-cell (Th17) cytokineinduced osteoclastogenesis. A: Peripheral blood $\mathrm{CD}_{14}{ }^{+}$monocytes were cultured with macrophage colony-stimulating factor and $50 \mathrm{ng} / \mathrm{mL}$ of IL-17 in the presence of signal inhibitors, such as $20 \mu \mathrm{mol} / \mathrm{L}$ of LY294002 (LY), $10 \mu \mathrm{mol} / \mathrm{L}$ of SB203580 (SB), 50 $\mu \mathrm{mol} / \mathrm{L}$ of $\mathrm{AG} 490(\mathrm{AG}), 10 \mu \mathrm{mol} / \mathrm{L}$ of parthenolide (PA), or $10 \mu \mathrm{mol} / \mathrm{L}$ of curcumin (CU). B: The expression of tartrate-resistant acid phosphatase (Trap), receptor activator of NF-KB (Rank), cathepsin K (Ctsk), calcitonin receptor (Calcr), and matrix metalloprotease (Mmp) 9 of the osteoclasts was determined using real-time PCR. The amount of mRNA expression was normalized by $\beta$-actin. The data were expressed as the relative mRNA expression of target $/ \beta$-actin. Data are presented as means \pm SEM of three separate experiments ( $A$ and B). ${ }^{*} P<0.05,{ }^{*} P<<0.01$, and ${ }^{* *} * P<0.005$.
After inhibition of p38 MAPK, STAT3, NF- $\mathrm{B}$, and AP-1 activities, differentiation into OCs was significantly decreased $(P<0.05)$ (Figure 9A). The expression of Trap, Ctsk, and Caler was significantly decreased after treatment with parthenolide and curcumin $(P<0.05)$ (Figure 9B).

\section{Discussion}

Periarticular osteopenia, joint space narrowing, and bony erosions are characteristic of bone involvement in RA. ${ }^{24}$ Dysregulated osteoclastogenesis and production of tissuedegrading molecules in response to inflammatory stimuli result in the destruction of cartilage and bones. ${ }^{25}$ Various inflammatory cytokines and immune cells are involved in the bony destructive process of RA. Among the destructive proteinases or cytokines produced by RA synovial and immune cells, RANKL is most important for bony destruction in RA. ${ }^{25}$ Activated $\mathrm{CD} 4^{+} \mathrm{T}$ cells and FLSs play a key role in osteoclastogenesis. ${ }^{26}$ They express RANKL and differentiate osteoclast precursors into osteoclasts in vitro. However, the regulatory role of $\mathrm{CD}^{+}{ }^{+} \mathrm{T}$ cells in osteoclastogenesis is still controversial. Both Th1 cytokines (ie, IL-12 and IL-18) and Th2 cytokines (ie, IL-4 and IL-10) generally inhibit osteoclastogenesis. Interferon $-\gamma$, a representative Th1 cytokine, strongly inhibits osteoclastogenesis, 


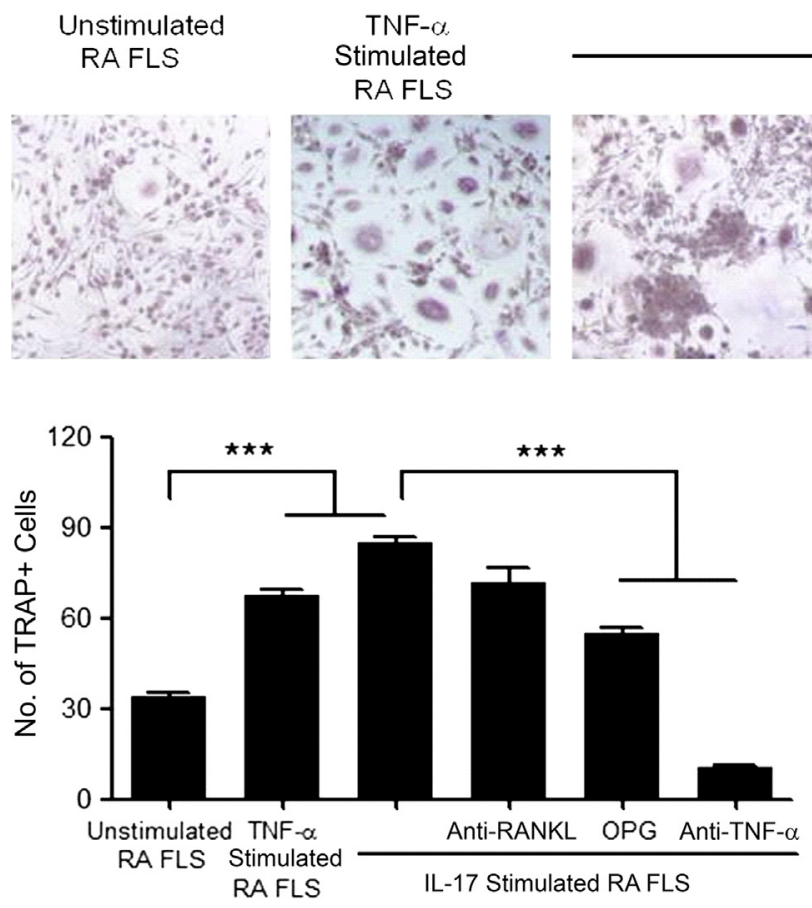

and normal Th1 cells do not induce osteoclastogenesis. Therefore, activated $\mathrm{CD}^{+}{ }^{+} \mathrm{T}$ cells can induce osteoclastogenesis indirectly through the up-regulation of other osteoclastogenic cytokines. In addition to RANKL, FLSs produce TNF- $\alpha$, IL-1, IL-6, IL-17, and prostaglandin $\mathrm{E}_{2}$, which stimulate osteoclast activation and differentiation.

IL-17 induces the production of proinflammatory mediators, such as IL-1 and TNF- $\alpha$ from several synovial cells, including synovial fibroblasts, macrophages, and chondrocytes. ${ }^{27,28} \mathrm{IL}-17$ also induces RANKL expression, which is crucial for osteoclastogenesis and bone resorption, ${ }^{29}$ and directly stimulates osteoclast differentiation in vitro. IL-17 promotes cartilage destruction and bone erosion in experimental arthritis models. ${ }^{10,30-33}$ IL-17 is an important mediator in the development of arthritis in CIA, and blockage of IL-17 by neutralizing antibodies reduces the development and severity of CIA.

In this study, IL-17 level correlated with RANKL level in RA synovial fluid. The correlation of their synovial levels was significant, and IL-17 increased RANKL activity in a luciferase assay in RA FLS. These results suggest that IL-17 regulates RANKL production in FLSs of RA. Apart from the activities of IL-17, there is evidence that other Th17 cytokines regulate RANKL production and osteoclast differentiation in RA. Recently, we showed that IL-22 is upregulated in RA synovial tissues, and it induces RANKL expression in RA FLS and osteoclastogenesis through the activation of the JAK2/STAT3 and p38 MAPK/NF- $\kappa$ B pathways. ${ }^{34}$ IL-21 is also up-regulated in synovial tissues and sera of RA patients, and it induces RANKL expression in FLS and enhances in vitro osteoclastogenesis. ${ }^{35}$ Although IL-21 is produced by Th17 cells, it also critically regulates Th17 cell development. ${ }^{36,37}$
IL-17-Stimulated RA FLS

\section{+ Anti-RANKL}

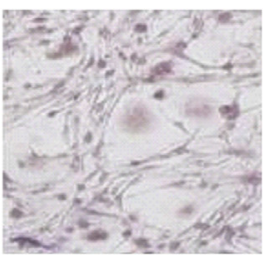

$$
+O P G
$$

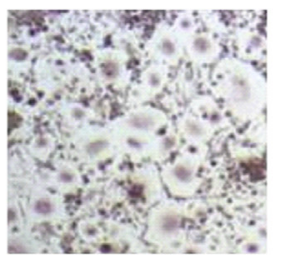

+ Anti-TNF- $\alpha$

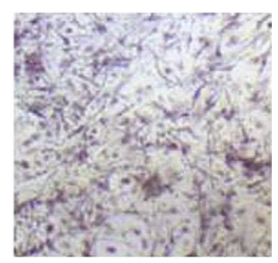

Figure 8 IL-17-prestimulated rheumatoid arthritis (RA) fibroblastlike synoviocytes (FLSs) induce osteoclast differentiation. RA FLSs were pretreated with $50 \mathrm{ng} / \mathrm{mL}$ of IL-17 for 3 days, and then monocytes were co-cultured with the IL-17-pretreated RA FLS for 3 weeks in $\alpha$-minimal essential medium containing $10 \%$ horse serum with $100 \mathrm{ng} / \mathrm{mL}$ macrophage colony-stimulating factor. The osteoclast differentiation was determined by counting tartrate-resistant acid phosphatase (TRAP) ${ }^{+}$ multinucleated cells. The figures are representative of three independent experiments. ${ }^{* *} P<0.005$. OPG, osteoprotegerin; RANKL, receptor activator of NF- $\mathrm{KB}$ ligand.

The major source of IL-17 in the CIA model is a subset of $\mathrm{CD}^{+}{ }^{+} \mathrm{T}$ cells, named Th17 cells. Th17 cells are essential to bone destruction in RA, and anti-IL-17 therapy and genetic IL-17 deficiency ameliorate disease severity and bone damage by reducing the number of osteoclasts in CIA. ${ }^{31} \mathrm{IL}-$ 17 and RANKL are highly expressed in RA synovial fluid and tissues, and they enhance osteoclastogenesis in vitro. ${ }^{23}$ IL-17 differentiates human peripheral blood monocytes into osteoclasts in the absence of osteoblasts or soluble RANKL, and TNF- $\alpha$ and RANKL synergistically induce osteoclastogenesis. ${ }^{16}$ Because RANKL is a key molecule for osteoclast activation and differentiation, we determined the ability of three different Th17 cytokines, IL-17, IL-21, and IL-22, to induce RANKL in FLS. In this study, Th17 cytokines induced RANKL expression in RA FLS, and IL-17 and IL-22 showed similar effects on the induction of RANKL expression, with no additive effect. IL-21 showed a lesser effect on RANKL induction than the other two Th17 cytokines. This result suggests that IL-17 and IL-22 are major cytokines for the induction of RANKL and the stimulation of osteoclast differentiation, and that IL-21 plays an accessory role in osteoclastogenesis by regulating Th17 cell differentiation.

Next, we determined Th17 cytokine-induced osteoclast differentiation through two approaches. First, peripheral blood monocytes were cultured with M-CSF and three Th17 cytokines in the absence of RANKL. The Th17 cytokines significantly induced osteoclast differentiation from monocytes. Similar to the pattern by which they induced RANKL expression, the effects of IL-17 and IL-22 were stronger than the effect of IL-21 in osteoclastogenesis; however, no additive effect of these cytokines was observed. Because Th17 cytokines share the same receptors as osteoclast 

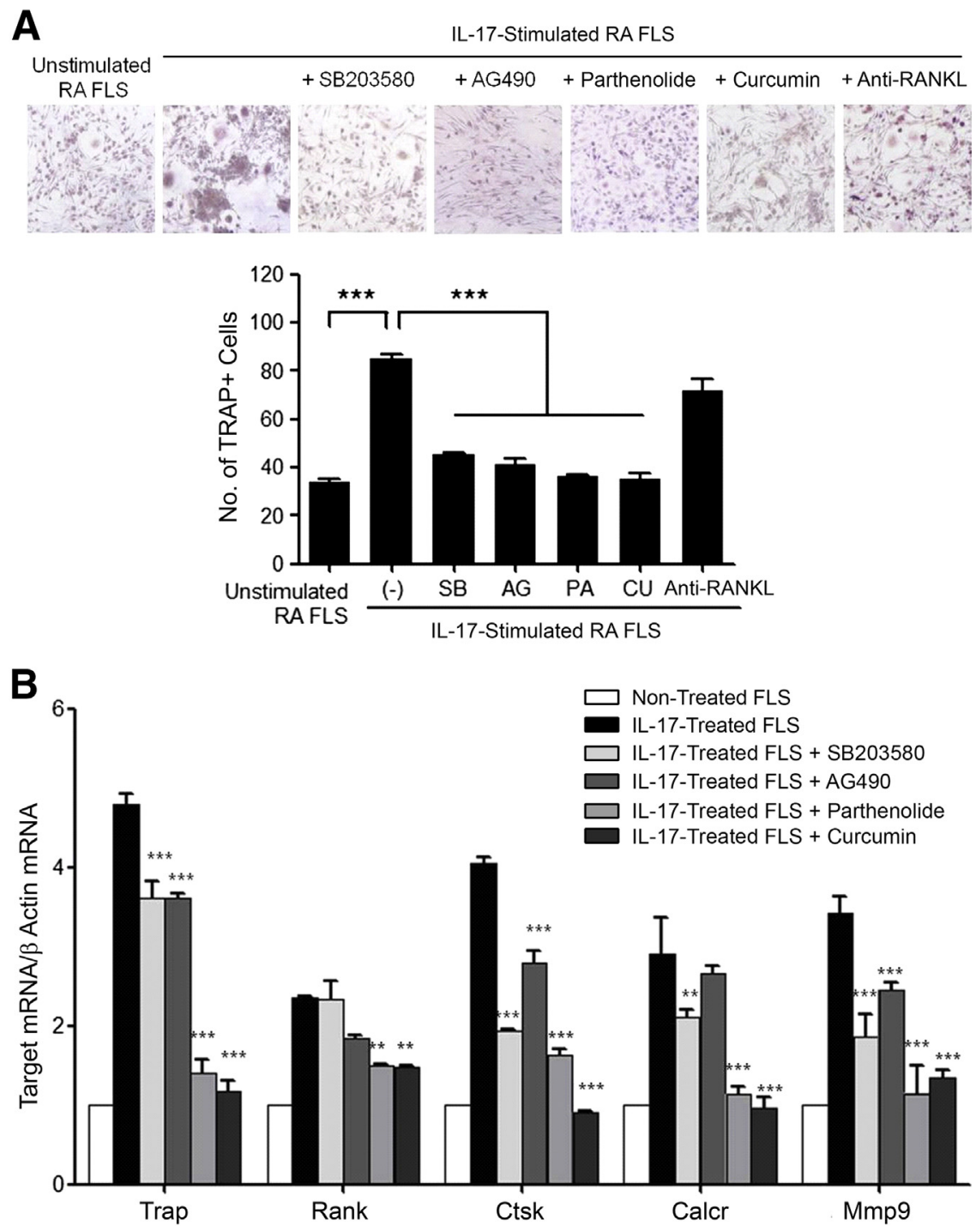

Figure 9 Intracellular signaling pathways involved in the induction of osteoclastogenesis by IL-17-stimulated rheumatoid arthritis (RA) synovial fibroblasts [fibroblast-like synoviocytes (FLSs)]. A: Peripheral blood $\mathrm{CD} 14^{+}$monocytes were cultured with macrophage colony-stimulating factor and IL-17-prestimulated RA FLS in the presence of signal inhibitors, such as $10 \mu \mathrm{mol} / \mathrm{L}$ of SB203580 (SB), $50 \mu \mathrm{mol} / \mathrm{L}$ of AG490 (AG), 10 $\mu \mathrm{mol} / \mathrm{L}$ of parthenolide (PA), $10 \mu \mathrm{mol} / \mathrm{L}$ of curcumin (CU), or anti-receptor activator of NF- $\mathrm{KB}$ ligand (RANKL). The figures are representative of three independent experiments. B: The expression of tartrate-resistant acid phosphatase (Trap), Rank, cathepsin K (Ctsk), calcitonin receptor (Calcr), and matrix metalloprotease (Mmp) 9 of osteoclasts was determined using real-time PCR. The amount of mRNA expression was normalized by $\beta$-actin. The data were expressed as the relative mRNA expression of target/ $\beta$-actin. Data are presented as means \pm SEM of three separate experiments $(\mathbf{A}$ and $\mathbf{B}) .{ }^{*} P<0.01,{ }^{* *} P<0.005$ precursors, they might not have an additive effect. The osteoclastogenic effect of IL-17 was similar to that of RANKL and TNF- $\alpha$, suggesting that IL-17 is one of the most effective inducers for osteoclastogenesis. The neutralization of TNF- $\alpha$ reduced the IL-17-induced osteoclastogenesis because there are different receptors and independent pathways among the cytokines and their reciprocal activations. These data suggest that TNF- $\alpha$ can mediate the IL-17-induced osteoclastogenesis, it has a stronger effect than IL-17, or it plays at the most final process than IL-17 or RANKL. Second, we exposed FLSs to IL-17 before they were co-cultured with osteoclast precursors. RA FLS can induce osteoclastogenesis when cultured with monocytes. ${ }^{26}$ In a real clinical setting, FLSs are exposed and responsive to many inflammatory cytokines and chemokines; hence, we designed the co-culture system of monocyte- and cytokines-pre-exposed FLS to mimic this milieu. When monocytes were cultured with IL-17preexposed FLS, more osteoclasts differentiated than that observed when monocytes were cultured with cytokine-unexposed FLS. This result suggests that IL-17 confers FLS with the potential to induce osteoclastogenesis. The inhibition of TNF- $\alpha$ or osteoprotegerin reduced the osteoclast differentiation culturing with IL17-prestimulated RA FLS, and the inhibitory effect of anti-TNF- $\alpha$ was more potent than anti-RANKL or osteoprotegerin.

The adaptor molecule known as Act1 is a critical mediator of IL-17 receptor family signaling. ${ }^{28,38}$ On IL-17 stimulation, Act1 is recruited to IL-17 receptors through its SEFIR domain, and it is required for IL-17-mediated expression of genes involved in inflammation. Act1deficient mice are protected from CIA development, resulting from the prevention of neutrophil infiltration into the synovium, bone erosion, and cartilage damage and reduction of type II collagen-specific antibody production. These results suggest that Act1 is a critical mediator in the pathogenesis of RA animal modes. ${ }^{14}$ TRAF6 has a key role in RANK signaling in osteoclastogenesis, and TRAF6 deficiency results in compromised differentiation and 
activation of osteoclasts. ${ }^{39}$ TRAF6 is overexpressed in RA synovium, and synovial TRAF6 is correlated with synovial score and inflammatory cell infiltration. ${ }^{40}$ TRAF3 is a proximal negative regulator of IL-17 receptor signaling. TRAF3 has been shown to greatly suppress IL-17-induced NF- $\kappa \mathrm{B}$ and MAPK activation and the subsequent production of inflammatory cytokines and chemokines. ${ }^{41}$ In this study, Act1 was induced by IL-17 stimulation in RA FLS in a dose-dependent manner, and when Act1 was blocked by siRNA, the IL-17-induced RANKL expression was completely inhibited. TRAF6 was also decreased with the blockage of Act1. These results show that the Act1/TRAF6 pathway is essential in IL-17-induced RANKL expression of RA FLS and that TRAF6 is a downstream molecule of Act1. In addition, the blockage of NF- $\kappa \mathrm{B}$ and AP-1 decreased IL-17-induced RANKL expression in RA FLS. This result suggests that up-regulation of RANKL by IL-17 is mediated through the Act1/TRAF6 pathway upstream and the NF- $\kappa \mathrm{B}$ and AP-1 pathways downstream.

In summary, Th17 cytokines regulate osteoclastogenesis in RA through the up-regulation of RANKL expression in FLS and the direct induction of osteoclast differentiation. The IL-17-induced RANKL expression and osteoclastogenesis were mediated by the Act1/TRAF6/NF- $\kappa$ B and AP1 pathways and TNF- $\alpha$. The blockage of this IL-17 and RANKL axis could be a new therapeutic target for bone destruction in RA.

\section{Acknowledgments}

K.-W.K. designed and performed the experiment and analyzed the data, K.-W.K. and H.-R.K. wrote the manuscript, B.-M.K. performed the experiments and analyzed the data, and S.-H.L. and M.-L.C. supervised the project.

\section{References}

1. Kotake S, Sato K, Kim KJ, Takahashi N, Udagawa N, Nakamura I, Yamaguchi A, Kishimoto T, Suda T, Kashiwazaki S: Interleukin-6 and soluble interleukin-6 receptors in the synovial fluids from rheumatoid arthritis patients are responsible for osteoclast-like cell formation. J Bone Miner Res 1996, 11:88-95

2. Gravallese EM, Harada Y, Wang JT, Gorn AH, Thornhill TS, Goldring SR: Identification of cell types responsible for bone resorption in rheumatoid arthritis and juvenile rheumatoid arthritis. Am J Pathol 1998, 152:943-951

3. Suryani S, Sutton I: An interferon-gamma-producing Th1 subset is the major source of IL-17 in experimental autoimmune encephalitis. J Neuroimmunol 2007, 183:96-103

4. Annunziato F, Cosmi L, Santarlasci V, Maggi L, Liotta F, Mazzinghi B, Parente E, Fili L, Ferri S, Frosali F, Giudici F, Romagnani P, Parronchi P, Tonelli F, Maggi E, Romagnani S: Phenotypic and functional features of human Th17 cells. J Exp Med 2007, 204:1849-1861

5. Acosta-Rodriguez EV, Rivino L, Geginat J, Jarrossay D, Gattorno M, Lanzavecchia A, Sallusto F, Napolitani G: Surface phenotype and antigenic specificity of human interleukin 17-producing $\mathrm{T}$ helper memory cells. Nat Immunol 2007, 8:639-646
6. Weaver CT, Harrington LE, Mangan PR, Gavrieli M, Murphy KM: Th17: an effector CD4 T cell lineage with regulatory T cell ties. Immunity 2006, 24:677-688

7. McKenzie BS, Kastelein RA, Cua DJ: Understanding the IL-23-IL-17 immune pathway. Trends Immunol 2006, 27:17-23

8. Hueber AJ, Asquith DL, Miller AM, Reilly J, Kerr S, Leipe J, Melendez AJ, McInnes IB: Mast cells express IL-17A in rheumatoid arthritis synovium. J Immunol 2010, 184:3336-3340

9. Parsonage G, Filer A, Bik M, Hardie D, Lax S, Howlett K, Church LD, Raza K, Wong SH, Trebilcock E, Scheel-Toellner D, Salmon M, Lord JM, Buckley CD: Prolonged, granulocyte-macrophage colonystimulating factor-dependent, neutrophil survival following rheumatoid synovial fibroblast activation by IL-17 and TNFalpha. Arthritis Res Ther 2008, 10:R47

10. Takayanagi H: Osteoimmunology: shared mechanisms and crosstalk between the immune and bone systems. Nat Rev Immunol 2007, 7: 292-304

11. Jovanovic DV, Di Battista JA, Martel-Pelletier J, Jolicoeur FC, He Y, Zhang M, Mineau F, Pelletier JP: IL-17 stimulates the production and expression of proinflammatory cytokines, IL-beta and TNF-alpha, by human macrophages. J Immunol 1998, 160:3513-3521

12. Adamopoulos IE, Sabokbar A, Wordsworth BP, Carr A, Ferguson DJ, Athanasou NA: Synovial fluid macrophages are capable of osteoclast formation and resorption. J Pathol 2006, 208:35-43

13. Fujikawa Y, Sabokbar A, Neale S, Athanasou NA: Human osteoclast formation and bone resorption by monocytes and synovial macrophages in rheumatoid arthritis. Ann Rheum Dis 1996, 55:816-822

14. Pisitkun P, Claudio E, Ren N, Wang H, Siebenlist U: The adaptor protein CIKS/ACT1 is necessary for collagen-induced arthritis, and it contributes to the production of collagen-specific antibody. Arthritis Rheum 2010, 62:3334-3344

15. Hartupee J, Liu C, Novotny M, Li X, Hamilton T: IL-17 enhances chemokine gene expression through mRNA stabilization. J Immunol 2007, 179:4135-4141

16. Yago T, Nanke Y, Ichikawa N, Kobashigawa T, Mogi M, Kamatani N, Kotake S: IL-17 induces osteoclastogenesis from human monocytes alone in the absence of osteoblasts, which is potently inhibited by antiTNF-alpha antibody: a novel mechanism of osteoclastogenesis by IL17. J Cell Biochem 2009, 108:947-955

17. Arnett FC, Edworthy SM, Bloch DA, McShane DJ, Fries JF, Cooper NS, Healey LA, Kaplan SR, Liang MH, Luthra HS, et al: The American Rheumatism Association 1987 revised criteria for the classification of rheumatoid arthritis. Arthritis Rheum 1988, 31:315-324

18. Kim HR, Cho ML, Kim KW, Juhn JY, Hwang SY, Yoon $\mathrm{CH}$, Park SH, Lee SH, Kim HY: Up-regulation of IL-23p19 expression in rheumatoid arthritis synovial fibroblasts by IL-17 through PI3-kinase-, NF-kappaB- and p38 MAPK-dependent signalling pathways. Rheumatology (Oxford) 2007, 46:57-64

19. Krotz F, de Wit C, Sohn HY, Zahler S, Gloe T, Pohl U, Plank C: Magnetofection: a highly efficient tool for antisense oligonucleotide delivery in vitro and in vivo. Mol Ther 2003, 7:700-710

20. Krotz F, Sohn HY, Gloe T, Plank C, Pohl U: Magnetofection potentiates gene delivery to cultured endothelial cells. J Vasc Res 2003, 40: 425-434

21. Brentano F, Schorr O, Gay RE, Gay S, Kyburz D: RNA released from necrotic synovial fluid cells activates rheumatoid arthritis synovial fibroblasts via Toll-like receptor 3. Arthritis Rheum 2005, 52: 2656-2665

22. Wu Y, Liu J, Feng X, Yang P, Xu X, Hsu HC, Mountz JD: Synovial fibroblasts promote osteoclast formation by RANKL in a novel model of spontaneous erosive arthritis. Arthritis Rheum 2005, 52:3257-3268

23. Kotake S, Udagawa N, Takahashi N, Matsuzaki K, Itoh K, Ishiyama S, Saito S, Inoue K, Kamatani N, Gillespie MT, Martin TJ, Suda T: IL-17 in synovial fluids from patients with rheumatoid arthritis is a potent stimulator of osteoclastogenesis. J Clin Invest 1999, 103:1345-1352

24. Firestein GS: Evolving concepts of rheumatoid arthritis. Nature 2003, 423:356-361 
25. Schett G, Gravallese E: Bone erosion in rheumatoid arthritis: mechanisms, diagnosis and treatment. Nat Rev Rheumatol 2012, 8:656-664

26. Maruotti N, Grano M, Colucci S, d'Onofrio F, Cantatore FP: Osteoclastogenesis and arthritis. Clin Exp Med 2011, 11:137-145

27. Lubberts E: IL-17/Th17 targeting: on the road to prevent chronic destructive arthritis? Cytokine 2008, 41:84-91

28. Dong C: Diversification of T-helper-cell lineages: finding the family root of IL-17-producing cells. Nat Rev Immunol 2006, 6:329-333

29. Adamopoulos IE, Chao CC, Geissler R, Laface D, Blumenschein W, Iwakura Y, McClanahan T, Bowman EP: Interleukin-17A upregulates receptor activator of NF-kappaB on osteoclast precursors. Arthritis Res Ther 2010, 12:R29

30. Chang SH, Park H, Dong C: Act1 adaptor protein is an immediate and essential signaling component of interleukin-17 receptor. J Biol Chem 2006, 281:35603-35607

31. Pollinger B, Junt T, Metzler B, Walker UA, Tyndall A, Allard C, Bay S, Keller R, Raulf F, Di Padova F, O’Reilly T, Horwood NJ, Patel DD, Littlewood-Evans A: Th17 cells, not IL-17+ gammadelta T cells, drive arthritic bone destruction in mice and humans. J Immunol 2011, 186:2602-2612

32. Chao CC, Chen SJ, Adamopoulos IE, Davis N, Hong K, Vu A, Kwan S, Fayadat-Dilman L, Asio A, Bowman EP: Anti-IL-17A therapy protects against bone erosion in experimental models of rheumatoid arthritis. Autoimmunity 2011, 44:243-252

33. Koenders MI, Marijnissen RJ, Devesa I, Lubberts E, Joosten LA, Roth J, van Lent PL, van de Loo FA, van den Berg WB: Tumor necrosis factor-interleukin-17 interplay induces S100A8, interleukin1beta, and matrix metalloproteinases, and drives irreversible cartilage destruction in murine arthritis: rationale for combination treatment during arthritis. Arthritis Rheum 2011, 63:2329-2339
34. Kim KW, Kim HR, Park JY, Park JS, Oh HJ, Woo YJ, Park MK, Cho ML, Lee SH: Interleukin-22 promotes osteoclastogenesis in rheumatoid arthritis through induction of RANKL in human synovial fibroblasts. Arthritis Rheum 2012, 64:1015-1023

35. Kwok SK, Cho ML, Park MK, Oh HJ, Park JS, Her YM, Lee SY, Youn J, Ju JH, Park KS, Kim SI, Kim HY, Park SH: Interleukin-21 promotes osteoclastogenesis in humans with rheumatoid arthritis and in mice with collagen-induced arthritis. Arthritis Rheum 2012, 64:740-751

36. Wei L, Laurence A, Elias KM, O'Shea JJ: IL-21 is produced by Th17 cells and drives IL-17 production in a STAT3-dependent manner. J Biol Chem 2007, 282:34605-34610

37. Nurieva R, Yang XO, Martinez G, Zhang Y, Panopoulos AD, Ma L, Schluns K, Tian Q, Watowich SS, Jetten AM, Dong C: Essential autocrine regulation by $\mathrm{IL}-21$ in the generation of inflammatory $\mathrm{T}$ cells. Nature 2007, 448:480-483

38. Novatchkova M, Leibbrandt A, Werzowa J, Neubuser A, Eisenhaber F: The STIR-domain superfamily in signal transduction, development and immunity. Trends Biochem Sci 2003, 28:226-229

39. Naito A, Azuma S, Tanaka S, Miyazaki T, Takaki S, Takatsu K, Nakao K, Nakamura K, Katsuki M, Yamamoto T, Inoue J: Severe osteopetrosis, defective interleukin-1 signalling and lymph node organogenesis in TRAF6-deficient mice. Genes Cells 1999, 4:353-362

40. Zhu LJ, Dai L, Zheng DH, Mo YQ, Ou-Yang X, Wei XN, Shen J, Zhang BY: Upregulation of tumor necrosis factor receptor-associated factor 6 correlated with synovitis severity in rheumatoid arthritis. Arthritis Res Ther 2012, 14:R133

41. Zhu S, Pan W, Shi P, Gao H, Zhao F, Song X, Liu Y, Zhao L, Li X, Shi Y, Qian Y: Modulation of experimental autoimmune encephalomyelitis through TRAF3-mediated suppression of interleukin 17 receptor signaling. J Exp Med 2010, 207:2647-2662 